\title{
¿CUÁL ES HOY LA HISTORIA DE LOS TRABAJADORES EN LA ARGENTINA?
}

\begin{abstract}
Juan Suriano*
Resumo: Este texto aborda algumas questões para o estudo dos trabalhadores argentinos. Até meados dos anos 1980, salvo algumas honrosas exceções, os estudos do mundo do trabalho não era uma preocupação central nos trabalhos acadêmicos. A renovação da historiografia, que enfatizou uma nova história dos trabalhadores, preocupada com a experiência da classe operária, superou aquela velha história contada por militantes e provocou um saudável debate na produção historiográfica até a década de 1990. Diante deste contexto, cumpre apontar algumas dificuldades para o exercício de renovação historiográfica e a sugerir alguns caminhos para realização deste esforço.
\end{abstract}

Palavras-chave: história dos trabalhadores (Argentina), historiografia do trabalho (Argentina).

Abstract: This paper addresses some issues for the study of Argentine workers. Until the first half of 1980s, apart from a few exceptions, the studies of the world of the workers were not a central concern in academic work. The renewal of the historiography, which emphasized a new history of workers, worried about the experience of the working class, over that old story told by activists and provoked a healthy debate on historiographical production until the 1990s. In this context, it indicates some difficulties in the exercise of historiographical renewal and suggests some ways to achieve this effort.

Keywords: history of workers (Argentina), history of work (Argentina).

En esta presentación intentaré abordar algunos de los problemas planteados por la historiografía de los trabajadores en Argentina. ${ }^{1}$ Es sabido que hasta mediados de los años 80 la visión del mundo del trabajo no era una preocupación central de la historia académica fuera de algunas honrosas excepciones. ${ }^{2}$ Sin embargo, hace aproximadamente unas dos décadas pareció abrirse una nueva etapa en los estudios sobre la clase obrera y los trabajadores argentinos que permitía pensar en la existencia de una "nueva historia de los trabajadores" basada en el planteo de nuevos temas y nuevas preocupaciones: la experiencia de la clase obrera, las condiciones de existencia material, la importancia del lugar del trabajo, el rol desempeñado por el Estado, la vida cotidiana y las comunidades, simbologías y ritualidades. Este movimiento renovador centraba su atención en aspectos sociales y culturales tratando de superar aquella vieja historia contada por los militantes que se centraban en la organización sindical y las huelgas. Los nuevos enfoques no sólo

\footnotetext{
* Instituto de Altos Estudios Sociales - Universidad Nacional de San Martín (IDAES/UNSAM).

${ }^{1}$ De ninguna manera haré una revisión exhaustiva de la bibliografía referida a la historia obrera. Sólo aparecerán en esta breve comunicación aquellos textos que sean imprescindibles a mi argumentación.

2 José Panettieri. Los trabajadores, Buenos Aires: Jorge Alvarez, 1967; Julio Godio. El movimiento obrero y la cuestión nacional. Argentina: inmigrantes, asalariados y lucha de clases, 1880-1910. Buenos Aires: Erasmo, 1972.
} 
renovaban los temas e incorporaban nuevas fuentes, sino también reinterpretaban y ponían en discusión conceptos claves como el de clase obrera provocaron el comienzo de un saludable debate que, lamentablemente, quedó inconcluso y generó consensos sin haber transitado por el tamiz de una discusión profunda. Además, ese impulso renovador fue breve y se detuvo en los años noventa y si bien aun no se han discutido las razones de esa paralización, podemos mencionar algunas posibles causas aclarando antes que, en Argentina, las dificultades de la historia de los trabajadores para producir una renovación y expansión de estos estudios se encuentra tensionada por otras cuestiones no necesariamente referidas a conceptos, teorías, metodologías y pugnas académicas.

Es principio, no es aventurado sostener que la historia de los trabajadores fue afectada por la crisis producida en el mundo del trabajo a partir de una serie de transformaciones estructurales de la economía capitalista a nivel mundial. Estos cambios que ifluyeron en los procesos de producción comenzaron en los años inmediatamente posteriores a la crisis petrolera de los años 70 y afectaron en mayor o menor medida a todo el campo capitalista y de manera particular al mundo de los trabajadores. "La crisis afectó también intensamente el universo de la conciencia, de la subjetividad del trabajo, de sus formas de representación". ${ }^{3}$ En este contexto los sindicatos se debilitaron, perdiendo en buena medida su capacidad de presión y negociación que los condujo a adoptar una actitud defensiva aceptando los temas de discusión impuestos por la agenda neoliberal y, en buena medida, participar y negociar con el orden impuesto por el capital y el mercado.

Esta crisis fue especialmente significativa en Argentina por la particular crudeza que adquirió el proceso de reconversión económica y la retirada del Estado en la regulación de las relaciones sociales durante los años 90 . Se produjo un verdadero colapso social cuya manifestación más visible es el aumento de la desocupación, la subocupación y el empleo eventual e informal que acrecentaron los niveles de pobreza en términos nunca vistos antes. Esta es una expresión adicional de que Argentina no es la de ayer, la aparición de una nueva categoría en el panorama de la pobreza: "los nuevos pobres", un grupo que se diferencia claramente de los "pobres estructurales" (aquellos que siempre fueron pobres) y que refiere a un conjunto de personas, en buena medida al mundo de los trabajadores, que

\footnotetext{
3 Ricardo Antunes. "Para donde vai o mundo do trabalho?" In: Angela M. C. Araújo (Ed). Trabalho, cultura e cidadania. São Paulo: Scritta, 1997, p. 106.
} 
perdieron sus empleos y se empobrecieron resignando cosas vitales para su calidad y condiciones de vida en el pasado.

Se advierte a su vez una situación relativamente nueva, al menos en el reconocimiento por parte de las mediciones estadísticas. Según datos oficiales del INDEC más mujeres trabajan o buscan trabajo. Alrededor del $54 \%$ de las mujeres entre 15 y 64 están actualmente ocupadas o buscando activamente un empleo. La mayor participación femenina en el mercado laboral que se registra desde la recesión iniciada hacia mediados de 1994 con las consecuencias del llamado efecto "tequila" no implica que los niveles de desocupación entre las mujeres no sean superiores a los de los hombres $(17,7 \%$ frente al 13,7\%). Femenización de las ocupaciones y del desempleo, precarización en general y para las mujeres en particular y compensación del desaliento laboral masculino por un mayor vuelco de las mujeres al mercado de trabajo; fragmentación de la dirigencia gremial y subordinación del sector vinculado al peronismo a las políticas ejecutadas por el gobierno nacional son algunas de las características que han convertido al estudio de los procesos de empobrecimiento y a las nuevas formas de la protesta social en el centro de las reflexiones de sociólogos y cientistas políticos que se refieren al pasado de manera muy general.

No son los únicos datos. El movimiento sindical ha sufrido también el impacto de las transformaciones iniciadas durante la dictadura militar en 1976 y profundizadas por el gobierno justicialista encabezado por el presidente Carlos Menem, debatiéndose hoy entre la pérdida de afiliados, la precarización y la subalternización de su rol. El movimiento obrero argentino amerita una larga tradición de lucha desde que a principios de siglo se constituyera bajo la orientación, no exenta de dificultades y limitaciones, de las corrientes anarquistas, sindicalistas revolucionarios, socialistas y, más tarde, comunistas como una organización gremial vigorosa en el contexto de los países latinoamericanos. Estas organizaciones contribuyeron a dotar a los trabajadores de una identidad definida así como también coadyuvaron a construir la ciudadanía social. Sería difícil comprender la obtención de los derechos laborales y de la activa presencia del Estado regulando las relaciones obrero-patronales durante la primera etapa peronista sin tener en cuenta la experiencia previa. Con posterioridad al golpe de 1955, el sindicalismo recorrió un camino convulsionado pero, tal vez, el más rico de su historia. Si por un lado alcanzó su mayor poderío y capacidad de presión bajo el ala de lo que se ha dado en llamar "burocracia sindical peronista", por otro, y simultáneamente, transitó un sendero de radicalización 
cuyo punto culminante fue el clasismo de los gremios cordobeses a comienzos de los años 70.

Como consecuencia de la crisis del trabajo y de sus organizaciones representativas se ha producido un desplazamiento de la historia de los trabajadores hacia los márgenes, colocando a los estudios sobre ellos en un lugar subordinado y en la necesidad de "reconceptualizar la clase obrera". ${ }^{4}$ Esta crisis de la historia obrera es la expresión de otra mayor: la de la crisis de una sociedad basada en el trabajo y en la difusión de los derechos asociados a su desenvolvimiento. ${ }^{5}$ Ocupando un lugar marginal, la historia de los trabajadores tiende a quedar como un dato cristalizado del pasado que los historiadores interesados en el tema no hemos podido (tal vez tampoco sabemos cómo) arrancar de su estado somnoliento, aunque los conflictos provocados por el desajuste social de las políticas neoliberales-piquetes, cortes de ruta, etc- tal vez sirvan de aliciente para dar un nuevo impulso a la historia obrera.

La pregunta básica es, si efectivamente ha existido durante los últimos años interés académico en los estudios sobre trabajadores. $Y$ la primera respuesta parece poco alentadora pues basta observar las muchas y diversas publicaciones de historia para darse cuenta de que este interés es absolutamente secundario en el conjunto de preguntas que se realiza hoy desde la historia académica argentina. Y si bien la mencionada crisis del mundo del trabajo es, seguramente, una de las principales causas de esta pérdida de interés, también debe mencionarse la incidencia de los paradigmas predominantes en el campo de la historia académica que han privilegiado los análisis del nivel político a partir tanto de la restauración y el funcionamiento de la democracia como de las tendencias imperantes en otras latitudes. ${ }^{6}$ Ha habido una fuga masiva de investigadores hacia el campo de la historia política. No estoy señalando esto como un dato negativo, sólo describiendo una situación de hecho. Tampoco es mi interés profundizar este tema aquí, sino señalar que una de las grandes limitaciones que ofrece la historia política en nuestro país es que tanto desde una lectura que privilegia la construcción de una esfera pública,

\footnotetext{
${ }^{4}$ Marcel van der Linden. "El fin del eurocentrismo y el futuro de la historia del trabajo: o por qué debemos y podemos reconceptualizar la clase obrera" en J. Paniagua, J.A. Piqueras y V. Sanz (eds), Cultura social y política en el mundo del trabajo. Valencia: Biblioteca Historia Social, 1999.

${ }^{5}$ Robert Castel. La metamorfosis de la cuestión social. Una crónica del salariado. Buenos Aires: Paidós, 1997.

6 Francois-Xavier Guerra. "El renacer de la historia política: razones y propuestas" In: J.A.Gallego. Hacia una nueva historia, Madrid: Universidad Complutense, 1992.
} 
cuanto de otra lectura efectuada desde arriba a través del análisis de las prácticas, ideas y discursos de los sectores dominantes, los trabajadores quedan excluidos de sus análisis. Posiblemente esta exclusión del sujeto trabajadores del estudio de las prácticas políticas no se deba sólo al desinterés de la historia política sino también a que, quizás, haya sido abonada por los propios investigadores de la historia obrera, al poner excesivo énfasis en las características apolíticas de los trabajadores durante el período agroexportador. El sistema electoral fraudulento y limitativo imperante hasta 1912, el gran porcentaje de extranjeros y el predominio del anarquismo habrían determinado la apatía política de los trabajadores y la consecuente ausencia de reclamos masivos de derechos políticos, contrariamente a lo que ocurría en buena parte de Europa. La reforma del sistema electoral o la decadencia del anarquismo no modificaron sustancialmente estas interpretaciones, más allá de prestar atención a la importancia que adquiría ahora la interpelación desde los partidos políticos a los obreros en tanto electores. ${ }^{7}$ Es evidente que ha estado ausente de la historiografía el esfuerzo por estudiar el significado de la ciudadanía para los trabajadores de la etapa agroexportadora. ${ }^{8}$

La crisis del mundo del trabajo actual y la pérdida de interés del campo historiográfico parecen conducirnos a una crisis de los estudios sobre trabajadores. Precisamente, por la convicción personal sobre estos problemas, me parece interesante plantear someramente los debates de los últimos años y pensar en algunos caminos posibles para vigorizar este campo historiográfico.

LOS PASOS DE LA HISTORIOGRAFÍA: HISTORIA Y MILITANCIA

La primera observación que debe destacarse es la estrecha relación entre militancia política y gremial y la colocación del problema obrero como central en la problemática social del país y en la historiografía. En efecto, ya desde fines del siglo XIX la militancia socialista, sea en sus vertientes más moderadas o en las más radicales,

\footnotetext{
7 Anibal Viguera. "Participación electoral y prácticas políticas en los sectores populares en buenos Aires, 19121922", Entrepasados, № 1, Comienzos de 1991.; Matthew B. Karush. Workers or Citizens. Democracia and identity in Rosario, Argentina (1912-1930). Albuquerqe: University of New Mexico Press, 2002.

${ }^{8}$ Uno de los mejores ejemplos en el abordaje del significado de la ciudadanía para los obreros lo constituye la obra de David Montgomery sobre Estados Unidos durante el siglo XIX David Montgomery. El ciudadano trabajador. Democracia y mercado libre en el siglo XIX norteamericano. México: Instituto Mora, 1997.
} 
denunciaron la situación de los trabajadores en Argentina en un contexto de profundas transformaciones socio-económicas. Militantes e intelectuales reformistas planteaban la necesidad de mejorar la situación de las clases menesterosas, de los trabajadores, organizar la producción, mejorar las condiciones de trabajo e impulsar la organización obrera. Ese impulso dado por las organizaciones gremiales y la militancia política y gremial ayudó a colocar la "cuestión obrera" como un punto central de la cuestión social y al Estado nacional debió involucrarse y tratar de encontrar algunas soluciones a las inéditas “cuestiones' que se planteaban al comenzar el siglo. ${ }^{9}$

Esta actitud militante tuvo sus efectos continuadores cuando los primeros historiadores del movimiento obrero reclamaron un lugar y un pasado para los trabajadores argentinos. ${ }^{10}$ Las historias obreras de los militantes historiadores como Diego Abad de Santillán, Sebastían Marotta y Jacinto Oddone primero, o las de Ruben Iscaro y Plácido Grela más tarde, marcaron el rumbo de aquellas historias en donde desfilaban organizaciones gremiales, congresos obreros y gestas de lucha proletaria. Todas esas historias estaban tensionadas por el fracaso de la propuesta alternativa del anarquismo o por el avance arrollador del peronismo como proyecto político y modelo de organización y participación de los trabajadores y tuvieron una línea de continuidad con las que en los años setenta intentaron reexaminar la trayectoria de los trabajadores y sus organizaciones. ${ }^{11}$

La relación entre trabajadores y política fue fundamental en la orientación de los trabajos de investigación de los años setenta y los debates articulados alrededor de la autonomía de la clase, la conciencia de clase y sus vínculos con el "partido revolucionario" que diseñaba el paradigma leninista. Los años conflictivos contemporáneos a la Revolución rusa constituyeron el centro de un debate que no se constituyó en el eje de ninguna confrontación historiográfica posterior, pese a la aparición del libro de Edgardo

\footnotetext{
9 Juan Suriano (compilador). La cuestión social en Argentina, 1870-1943. Buenos Aires: La Colmena, 2000.

10 Leandro Gutierrez y Mirta Lobato. "Memorias militantes: un lugar y un pasado para los trabajadores argentinos", Entrepasados, № 3, Fines de 1992.

${ }^{11}$ Julio Godio. El movimiento obrero y la cuestión nacional. Argentina: inmigrantes, asalariados y lucha de clases, 1880-1910. Buenos Aires: Erasmo, 1972.; Jorge Solomonoff, Ideologías del movimiento obrero y conflicto social, Buenos Aires: Proyección, 1971.
} 
Bilsky. La Semana Trágica quedó como un episodio violento del pasado y como el punto que permitía denunciar la insensibilidad del gobierno radical en el gobierno. ${ }^{12}$

Por otra parte, el campo argentino con su potencial conflictivo fue en buena medida marginado de esta historiografía cuya centro social y político así como su potencial revolucionario sólo podía ser encarnado por los trabajadores industriales urbanos. $^{13}$

En los años setenta, el descubrimiento realizado por parte de los intelectuales de la capacidad de trasformación del peronismo y de su peso en las organizaciones sindicales, a las que se juzgaba en el centro de toda acción política, trajo una ráfaga de aire nuevo en el orden de los temas aunque no en los modos de hacer historia sobre los trabajadores. Las respuestas al trabajo pionero de Gino Germani ${ }^{14}$ sobre el surgimiento del peronismo y el papel de los trabajadores industriales urbanos nativos que habían conformado una nueva clase obrera dieron lugar a una vasta bibliografía. ${ }^{15} \mathrm{EI}$ peronismo se constituyó en el eje articulador de una amplia producción y por su peso en la historia del país y en la historia personal de los investigadores opacaron toda la historia de los trabajadores anterior a su formación. Los sindicatos y la relación establecida con Perón fue un fuerte tópico articulador de las investigaciones que trataban de explicar la pérdida de autonomía de la clase obrera frente al líder y al partido político burgués. El populismo

\footnotetext{
12 David Rock. "La Semana Trágica y los usos de la historia”, Desarrollo Económico, № 42-44, julio de 1971marzo de 1972. Idem. "Lucha civil en la Argentina. La Semana Trágica de enero de 1919", Desarrollo Económico, No 45, junio de 1972. Edgardo Bilsky. La FORA y el movimiento obrero. Buenos Aires: CEAL, 1985. Daniel Lvovich ha desarrollado reciente una novedosa línea de interpretación según la cual la magnitud de los acontecimientos de la Semana Trágica se habrían debido en buena medida a la manifestación de miedo y a la ola de rumores generada en y por los sectores dominantes Daniel Lvovich. Nacionalismo y antisemitismo en la Argentina. Buenos Aires: Javier Vergara, 2003.

13 Recién a comienzos de la década de 1990 comenzaron a aparecer trabajos embrionarios sobre la conflictividad y la organización de los trabajadores rurales (Waldo Ansaldi (Compilador). Conflictos obrerorurales pampeanos (1900-1937). Buenos Aires: CEAL, 1993) que fueron pertinentemente criticados por Palacio. Ver: Juan Manuel Palacio. “¿Revolución en las Pampas? Comentario a: Conflictos obrero-rurales pampeanos de Waldo Ansaldi, Comp)”, Desarrollo Económico, № 140, enero-marzo de 1996.).

${ }^{14}$ Gino Germani. Política y sociedad en una época de transición. De la sociedad tradicional a la sociedad de masas, Buenos Aires: Paidós, 1966.

${ }^{15}$ Miguel Murmis y Juan Carlos Portantiero. Estudios sobre los orígenes del peronismo, Siglo XXI, Buenos Aires, 1972.; H. Matsushita. Movimiento obrero argentino 1930-45; sus proyecciones en los orígenes del peronismo. Buenos Aires: Siglo Veinte, 1983.; Marcelo Cavarozzi. Sindicatos y política en Argentina, 1955-58, Buenos Aires: CEDES, 1979.; Hugo del Campo. Sindicalismo y peronismo: los comienzos de un vínculo perdurable, Buenos Aires: FLACSO, 1983.; Juan Carlos Torre. La formación del sindicalismo peronista. Buenos Aires: Legasa, 1988. Torre. La vieja guardia sindical y Perón. Sobre los orígenes del peronismo. Buenos Aires: Sudamericana, 1990. y Daniel James. Resistencia e integración. Buenos Aires: Sudamericana, 1990. La bibliografía citada no es exhaustiva y sólo se mencionan los títulos más siginificativos.
} 
fue una clave para entender los derroteros políticos de una clase obrera que se mostraba esquiva a los postulados de la izquierda. El peronismo no era ni una propuesta de clase ni una opción para la izquierda de tradición marxista pero era de algún modo la expresión de los trabajadores.

La polémica que se inició a partir de los trabajos de Germani articulada alrededor del peronismo fue una de las más fructíferas. El sociólogo italiano ponía énfasis en los aspectos de ruptura, que la irrupción masiva de los migrantes internos - adherentes al peronismo - desempeñaron en la gestación del nuevo movimiento político. Una "nueva clase obrera" venía a desalojar a una "vieja" y poco conocida, la escasa experiencia de los nuevos trabajadores que carecían de conocimientos y prácticas organizacionales y se encontraban en estado de disponibilidad fue lo que les permitió seguir el liderazgo de Perón. El peronismo significaba, entonces, una fractura histórica que hacia fines de los años sesenta comenzó a ser cuestionada por quienes enfatizaban el rol del movimiento obrero organizado en los orígenes del peronismo y discutían básicamente la diferenciación establecida entre obreros nuevos y viejos así como la relación entre sindicalismo y Estado.

Como se ha señalado en otra oportunidad la mayoría de esos trabajos se enmarcaban alrededor de las ideas de continuidad o ruptura, de racionalidad e irracionalidad, de autonomía o heteronomía. El estado actual de las investigaciones ha inclinado la balanza hacia las ideas de la continuidad aunque es cierto que algunos textos reubican los términos de la ruptura en la nueva identidad política de los trabajadores, y en la invención de una tradición y una simbología que los aleja de las tradiciones del pasado. ${ }^{16}$

Si bien el tema de las relaciones entre la clase obrera y el peronismo constituyó una fuente importante de estímulos, con la excepción de los ya clásicos trabajos de Walter Little y Louise Doyon sobre conflictividad obrera y organización sindical ${ }^{17}$ o las recientes y embrionarias investigaciones sobre el rol de los trabajadores en la formación del peronismo en diversas provincias del interior del país, ${ }^{18}$ no se ha producido aún una

\footnotetext{
16 Juan Carlos Torre. La vieja guardia sindical y Perón. Sobre los orígenes del peronismo. Buenos Aires: Sudamericana, 1990; Daniel James. Resistencia e integración. Buenos Aires: Sudamericana, 1990.

17 Luise Doyon. "El crecimiento sindical bajo el peronismo", La organización del movimiento sindical peronista" y"Conflictos obreros durante el régimen peronista" en Juan C. Torre. La formación del sindicalismo peronista, Buenos Aires: Legasa, 1988. Walter Little. "La organización obrera y el Estado peronista" In: Juan C. Torre. La formación...

${ }^{18}$ Darío Macor y Cesar Tcach (editores). La inveción del peronismo en el interior del país. Santa Fe: Universidad Nacional del Litoral, 2003.
} 
lectura cultural del período y menos aún se ha escrito una historia social de los trabajadores que analice la complejidad de los vínculos y experiencias que los obreros establecieron entre sí, con los empresarios y con el propio Estado. El período posterior a la caída de Perón y, en particular la etapa de la resistencia peronista atrajo el interés de algunos jóvenes historiadores que, bajo el impacto del libro de Daniel James, se abocaron a examinaron los caminos de la protesta política en algunas localidades. ${ }^{19}$ De todos modos, se trata de estudios más acotados que la propia propuesta de James. Sin embargo, la historia del peronismo, de las organizaciones gremiales y de las políticas estatales no ha dado aún un cuadro social del período peronista y ha colocado un serio problema en la producción historiográfica que se acostumbró a pensar en función del punto llegada - los trabajadores y Perón - y se descuidaron las especificidades de cada época.

\section{LOS DEBATES INCOMPLETOS}

Sobre las condiciones de vida

A comienzos de los años 80 pareció abrirse un debate sobre las condiciones de vida de los trabajadores en tiempos de la inmigración masiva. Leandro Gutiérrez, familiarizado e identificado con la obra de los marxistas ingleses como Eric Hobsbawn y Edward P. Thompson, y retomando una tradición iniciada por Adrián Patroni y que, hasta aquí, había tenido su mejor expresión en la ya clásica obra de José Panettieri, ${ }^{20}$ colocaba en una clave problemática las interpretaciones optimistas encabezadas por Roberto Cortés Conde. ${ }^{21}$ La menor importancia de los salarios reales frente a la incertidumbre de los ciclos de ocupación y desocupación; el deterioro de la calidad de vida frente al incremento del consumo, la sobreexplotación frente a la tendencia a la suba de los salarios reales. La noción rígida de nivel de vida sustentada en la medición de los salarios reales fue cuestionada pero no fructificó en la constitución de trabajos que reprodujeran y afianzaran la versión pesimista. No se cuestionaron las series salariales siguiendo los

\footnotetext{
19 Ernesto Salas. La resistencia peronista: la toma del frigorífico Lisandro de la Torre. Buenos Aires: CEAL, 1990 ; Julio Melón. "La resistencia peronista. Alcances y significados" en Anuario, № 8, Tandil, 1993.

20 José Panettieri. Los trabajadores. Buenos Aires: Jorge Alvarez, 1967.

${ }^{21}$ Leandro Gutierrez. Vida material y experiencias de los sectores populares, Buenos Aires, 1880-1914”, Revista de Indias, № 163-164, Sevilla, 1981.
} 
mismos métodos ni se elaboró un cuadro del consumo de las familias obreras durante esas décadas. El cuadro impresionista se mantuvo y siguió persistiendo de manera casi imperturbable la noción de una Argentina próspera, abierta a la aventura del ascenso social.

El análisis sobre la vivienda en Buenos Aires y Rosario que había sido lúcidamente colocado como parte de la cuestión social ${ }^{22}$ se reprodujo en una amplia lectura sobre las condiciones mismas de la ciudad. Pero fueron escasos los historiadores argentinos que asociaron los problemas de vivienda a los trabajadores. La huelga de inquilinos de 1907 y las relaciones entre política, trabajadores y vivienda en Rosario fueron los temas que permitieron establecer esos nexos. Las desigualdades entre oferta de vivienda y crecimiento de la población produjo un encarecimiento de la vivienda urbana que afectó particularmente a los asalariados. Hacinados en conventillos, viviendo de manera precaria e indefensos ante propietarios y rentistas los trabajadores siguieron en pocos casos el camino de la protesta y el Estado no articuló una política en ese orden. ${ }^{23}$

Estos trabajos aportaron su visión al campo de la historia de los trabajadores desde el estudio de la cultura material con una pátina claramente pesimista pero no alcanzaron a provocar una controversia con las interpretaciones optimistas al estilo del que se había producido en el campo académico inglés. ${ }^{24}$

Sobre el mercado de trabajo

Más que un debate parece haberse articulado un consenso historigráfico alrededor de la caracterización del mercado de trabajo en la Argentina. En los análisis se cruzan las interpretaciones que abrevan en la teoría marxista y weberiana clásicas sobre el tema de la conformación de los mercados. En las versiones clásicas de Marx, se sitúa la división central de las clases en las relaciones de producción, mientras que Weber las

\footnotetext{
22 Oscar Yujnovsky. "Políticas de vivienda en la ciudad de Buenos Aires, 1880-1914”, Desarrollo Económico, № 54, Julio-Septiembre de 1974.

${ }^{23}$ Diego Armus y Jorge E. Hardoy. "Conventillos, ranchos y casa propia en el mundo urbano del novecientos" In: Diego Armus (Comp.), Mundo urbano y cultura popular. Estudios de historia social argentina. Buenos Aires: Sudamericana, 1990. Agustina Prieto. "Condiciones de vida en el barrio refinería de Rosario. La vivienda de los trabajadores (1890-1914)”, Anuario, № 14, Rosario, 1991; Suriano. "La huelga de inquilinos de 1907” en AAVV, Sectores populares...,1984.

24 J. Taylor. El nivel de vida en Gran Bretaña durante la revolución industrial. Madrid: Ministerio de Trabajo y Seguridad Social, 1985.
} 
define según el acceso diferencial a las recompensas de mercado. Marx concibe la producción como una estructura objetiva de relaciones entre clases, Weber analiza los motivos y las estrategias de la gente de acuerdo a como pugnan por aumentar su participación en los beneficios sociales. Marx pone el acento en la explotación y por eso enfatiza las relaciones de producción alrededor de las cuales se produce una polarización entre explotadores y explotados, para Weber hay una multiplicidad de demandas de los grupos organizados que luchan, precisamente, por conseguir un acceso privilegiado al mercado. Marxistas y weberianos se defendieron y atacaron mutuamente, sin embargo los desarrollos recientes han tendido a diluir las especificidades en las perspectivas de cada uno pero los teóricos marxistas tuvieron una mayor apertura hacia las concepciones weberianas. Estas conceptualizaciones han influido en los análisis que sobre la formación y características del mercado laboral se hicieron para la Argentina.

El análisis sobre los mercados se ha reproducido en muchos trabajos regionales que nos permiten ubicar a los trabajadores en la estructura productiva. Además, aunque se plantea una crítica a la idea de Cortés Conde de compensación automática de los desajustes entre oferta y demanda de mano de obra se presta poca atención a la dimensión social. El trabajo de Ofelia Pianetto es una voz aislada en el establecimiento de alguna conexión entre el funcionamiento del mercado de trabajo y la acción sindical. ${ }^{25}$ Por su parte el libro de Sabato-Romero refleja bastante bien los cambios operados en los análisis sobre clases . La experiencia del mercado es el subtítulo de un libro que se refiere a un período poco estudiado en la temprana formación de la clase trabajadora entre 1850 y 1880. En la conformación de los trabajadores se advierten varios elementos: el origen difuso de los trabajadores con brazos provenientes de la población nativa, algunos esclavos liberados e inmigrantes, la formación de un mercado laboral altamente homogéneo que no significó la descualificación de los trabajadores calificados (en otros países se explica por la desaparición del artesano), se impulsaron las ocupaciones autónomas y se verificó la existencia de una clara segmentación por sexo. ${ }^{26}$

\footnotetext{
${ }^{25}$ Ofelia Pianetto. "Mercado de trabajo y acción sindical en la Argentina, 1890-1922", Desarrollo Económico, Vol. 24, № 94, julio-setiembre de 1984.

${ }^{26}$ Hilda Sabato y Luis Alberto Romero. Los trabajadores de Buenos Aires. La experiencia del mercado, 18501880. Buenos Aires: Sudamericana, 1992.
} 
Pero son los resultados de la "experiencia del mercado" los que hacen de esta interpretación una lectura de las dimensiones sociales. La conformación de un espacio autónomo de trabajo reforzó las percepciones de las posibilidades de ascenso social y la creación de una fuerza de trabajo ocasional, muchas veces inestables pero atraídas por los salarios, delineó el poco interés de los trabajadores para el logro de mayores habilidades y destrezas por medio de la educación y se amortiguaron las acciones de protestas. Es esta imagen donde los conflictos parecen diluirse la que resulta poco convincente porque las manifestaciones de tensión - aunque no fueran cuantitativamente significativas - daban cuenta de los desajustes que el proceso de modernización producía. ${ }^{27}$

\section{Sobre clase obrera o sectores populares}

La influencia de los historiadores marxistas ingleses proponiendo reelaboraciones teóricas y reflexiones metodológicas conformaron nuevas formas de pensar la historia obrera que se sumaron a los viejos núcleos del pasado, produciendo en ellos una saludable modificación y apertura a temas novedosos y escasamente transitados hasta entonces: la historia de los trabajadores y no del movimiento obrero organizado; ${ }^{28}$ el concepto de clase como resultado de un proceso histórico en el que confluyen la experiencia de la nueva sociedad industrial y las tradiciones previas de los trabajadores en el que estos se constituyen como sujetos sociales, ${ }^{29}$ la cultura como campo de tensión ${ }^{30}$ o la historia

\footnotetext{
${ }^{27}$ En la provincia de Buenos Aires manifestaciones de las tensiones que el proceso de modernización generaba son las actitudes de xenofobia de la población nativa-gaucha en Tandil. Ver Juan Carlos Torre: "Los crímenes del Tata Dios, el mesías gaucho",en Todo es Historia, 4, Agosto de 1967, Hugo Nario: Tata Dios. El mesías de la última montonera. Buenos Aires: Plus Ultra, 1976 y Los crímenes del Tandil, 1872, Buenos Aires: CEAL, 1983. Para otras regiones del país se pueden consultar Noemí Goldman: "El levantamiento de montoneras contra "gringos" y "masones" en Tucumán, 1887: Tradición oral y cultura popular", Boletín, No. 2, Instituto de Historia Argentina y Americana Dr. Emilio Ravignani, 3a. Serie, 1er. Semestre de 1990, Leopoldo Bartolomé: "Movimientos milenaristas de los aborígenes entre 1905 y 1933", Cuaderno antropológico, Universidad Católica de Asunción del Paraguay, Vol. 7 Nos. 1-2, 1972 y Gustavo L. Paz: "Resistencia y rebelión campesina en la puna de Jujuy, 1850-1875, Boletín, No. 4, del Instituto de Historia Argentina y Americana Dr. E. Ravignani, $3 a$. Serie, 2do. Semestre de 1991.

${ }^{28}$ Eric Hobsbawm. Trabajadores. Estudios de historia de la clase obrera, Barcelona: Crítica, 1979. Idem. EI mundo del trabajo. Estudios históricos sobre la formación y evolución de la clase obrera. Barcelona: Crítica, 1987.

${ }^{29}$ E.P. Thompson. La formación de la clase obrera en Inglaterra. Barcelona: Crítica, 1980.

30 Stuart Hall. "Notas sobre la reconstrucción de lo popular" In: Raphael Samuel Ed. Historia popular y teoría socialista. Barcelona: Crítica, 1984.
} 
desde abajo y la historia de la gente común impulsada por el grupo de History Workshop. ${ }^{31}$ Esta historiografía renovadora de izquierda se alejaba tanto de las interpretaciones marxistas clásicas como de la vertiente estructuralista y se abrían a interpretaciones en donde los aspectos culturales y sociales cumplían ahora un rol central, aunque sin dejar de prestar atención a las esferas de lo político y lo económico. Estos trabajos pioneros dejaron su impronta en la historiografía europea occidental, generaron ricas y complejas polémicas $^{32}$ y renovaron la historia obrera. En cierta forma también lo hicieron en Argentina aunque tardíamente puesto que recién se generalizó su circulación después de la caída de la dictadura militar. También hay que destacar que la influencia de la historiografía marxista británica se notó mucho más en la lectura y discusión de esos textos que en la producción concreta.

En efecto, no fueron muchos los historiadores argentinos que transitaron el campo de análisis de la cultura con el objeto de repensar la historia obrera. En cierta forma, uno de los intentos más novedosos se vinculó al replanteo de los sujetos históricos, y esta cuestión se vinculaba directamente con la reformulación de la noción de clase que era una preocupación generalizada en el mundo occidental. En un artículo de mediados de los años 80 se planteaba que en las sociedades urbanas latinoamericanas las clases subalternas no debían referirse solamente a los trabajadores industriales sino incluir a grupos más amplios, derivando este planteo en la acuñación de una nueva categoría: los sectores populares. ${ }^{33}$ Una categoría que no tiene límites precisos "incluye y no incluye a todos los grupos y capas habitualmente considerados dudosos (ya se trate de pequeños comerciantes o delincuentes) $)^{\prime 34}$ pero que indudablemente también contiene en su seno a los trabajadores y a la clase obrera. Ahora bien, la comodidad del empleo de este término para referir a una sociedad caracterizada por una gran movilidad social y con un exiguo mundo del trabajo industrial le permitió instalarse cómodamente y canonizarse en la historiografía de los años 90 y reproducirse en trabajos vinculados a la historia obrera así

\footnotetext{
31 Raphael Samuel Ed. Historia popular y teoría socialista. Barcelona: Crítica, 1984.

32 La más conocida de y estimulante de ellas es el debate entre E. P. Thompson y Perry Anderson. Para un minucioso análisis de dicho debate véase: José Sazbon. "Dos caras del marxismo inglés. El intercambio Thompson-Anderson", Punto de Vista, № 29, Abril-julio de 1987.

33 Luis Alberto Romero. "Los sectores populares en las ciudades latinoamericanas del siglo XIX: la cuestión de la identidad" en Leandro Gutierrez y Luis Alberto Romero, Sectores populares, cultura y política. Buenos Aires en la entreguerra. Buenos Aires: Sudamericana, 1995 ( la versión original fue publicada en Desarrollo Económico, Vol. 27, № 106, julio-setiembre de 1987).

34 Romero, 1995: 37
} 
como a aquellos que hacían referencia a una cultura barrial, generalmente limitada a la ciudad de Buenos Aires. Quiénes acuñaron el concepto de sectores populares al buscar recortar un área de la sociedad que diera cuenta de las complejidades del proceso de conformación de los sujetos sociales fue desdibujando el rostro de los trabajadores (y de la clase obrera) en el seno de un magma complejo y difuso, desplazando a un segundo plano las complejidades de su experiencia (incluyendo el conflicto) al quedar subsumida en los análisis empíricos de sus capas más acomodadas beneficiadas por la movilidad social. De allí se desprende la imagen de una sociedad escasamente conflictiva cuyos elementos contestatarios moldeados por el anarquismo fueron sufriendo, después de la Primera Guerra, una paulatina disolución gracias al ascenso social y dando lugar a otra en donde el concepto sectores populares daría cuenta mejor de esa móvil (en sentido ascendente) y cambiante sociedad.

Este nuevo concepto así como aportaba matices teóricos y metodológicos a las más rígidas formas tradicionales de analizar al movimiento obrero, especialmente con la incorporación del nivel de la cultura, también denotaba una serie de limitaciones entre las cuales la señalada en el párrafo anterior no es la menor, y esas dificultades nublaban no sólo el perfil de la clase obrera sino también el propio surgimiento del peronismo. Pero, más allá de las críticas que hoy podamos efectuar a esta interpretación no hay dudas que unos de sus grandes méritos consistió en que se ubicó en el centro de una controversia que, lamentablemente, no alcanzó las formas de un debate escrito. En primer lugar porque las críticas aquí apenas esbozadas no afloraron en su momento y en segundo término porque quienes sí discutían esta postura lo hacían en un tono de denuncia por el abandono de la categoría marxista que se aproximaba al esencialismo y no desplegaba un arsenal teórico y empírico que le permitiera debatir con solidez las argumentaciones desplegadas en torno al concepto de sectores populares. ${ }^{35}$ El problema de esta crítica es su extremado apego a un supuesto conocimiento científico (nunca especificado con claridad) que parece tener una vía única y excluyente de interpretación, negando la importancia de la propia experiencia vivida por la clase obrera y como ella misma interpreta esas experiencias en términos de identidad de clase. Como sostiene este autor: "No se trata pues de 'recuperar

\footnotetext{
35 Nicolás Iñigo Carrera. "La huelga general de masas de 1936: un hecho borrado de la historia de la clase obrera argentina”, Anuario, IEHS, № 9, Tandil, 1994. Idem. La estrategia de la clase obrera, 1936. Buenos Aires: La Rosa Blindada-PIMSA, 2000.
} 
la memoria` sino de investigar científicamente los hechos". ${ }^{36}$ Pero esa "investigación científica" es una enumeración de acontecimientos (organización gremial, huelgas, etc) escasamente diferente a la versión de la vieja historia militante que explica muy poco cual es (y ha sido) la peculiaridad de la clase obrera argentina.

\section{Sobre Clase y etnicidad}

El concepto de clase no fue el único en ser colocada en discusión en los años ochenta. Las nociones de asimilacionismo, equilibrio y funcionalidad pilares de las corrientes anglosajonas que habían tenido un claro difusor con Gino Germani fueron discutidos y reemplazados por los de etnicidad y pluralismo. La lectura crítica de Germani no era realizada solamente por quienes pensaban el fenómeno peronista pues los vínculos entre inmigrantes y política también impulsaban un examen crítico de sus trabajos. Este examen crítico se realizó al amparo también de la crisis de los paradigmas que implicaba la crisis de las grandes interpretaciones (de los grandes relatos) y también la de los sujetos universalisadores. Cabe agregar que en la producción histórica anterior a los años ochenta la palabra "etnicidad" no tenía el valor explicativo y problemático que adquirió en las corrientes anglosajonas, sobre todo después de la segunda guerra mundial. Al impacto de los estudios sobre grupos étnicos en los Estados unidos y Canadá se reprodujeron las investigaciones sobre las comunidades italianas y españolas. Pero al concentrarse sobre las instituciones fueron desdibujando las diferencias de clase existentes en su seno. El dilema crucial era cómo resolver las tensiones entre una identidad étnica que se construía en el país receptor a expensas de las identidades regionales y una identidad de clase que a veces tendía a borrar esas diferencias a fuerza de vocear un internacionalismo proletario.

Ricardo Falcón ha estudiado las relaciones entre cuestión étnica, cuestión social y cuestión política. Es quizás uno de las pocas investigaciones que cruzan las tres claves problemáticas de la historia de comienzos de siglo en la Argentina y, para hacerlo, focaliza en el espacio que para las propuestas anarquistas y socialistas tenía esta dimensión. ${ }^{37}$ Este autor y Suriano coinciden en señalar que la dinámica internacionalista de los anarquistas y una

\footnotetext{
36 Iñigo Carrera, 1994: 291

37 Ricardo Falcón. Los orígenes del movimiento obrero, 1857-1890, CEAL, Buenos Aires, 1985. Idem. El mundo del trabajo urbano (1890-1914). Buenos Aires: CEAL, 1986.
} 
propuesta destinada a los desarraigados (independientemente de su origen étnico nacional y de su clase) fue la respuesta más adecuada para los trabajadores argentinos de la era del progreso. $^{38}$

En otro trabajo se intentó mostrar que las sociedades étnicas representaron una alternativa moderada al movimiento obrero militante. ${ }^{39}$ Para este autor el mutualismo étnico y el sindicalismo obrero cosmopolita coexistieron en una compleja relación de complementariedad y competencia. Al señalar la existencia de conflictos intraétnicos que se daban por ejemplo entre patronos y obreros (también entre inquilinos y propietarios) las diferencias parecían licuarse en el lugar de trabajo, dando paso a las tensiones producto de la desigual ubicación en el proceso productivo.

En oposición, el trabajo de Edgardo Bilsky, al estudiar los trabajadores de origen judío parece más convincente en su desarrollo y conclusiones. En primer lugar porque se trata de un grupo claramente diferenciado y localizado aunque el barrio en el que se asentaron no llegó a transformarse en un ghetto. En segundo lugar, al abordar los problemas intraétnicos coloca en un lugar privilegiado las tensiones entre trabajadores y patrones judíos y la élite comunitaria. Elite que por otra parte percibe a los militantes trabajadores como un elemento social perturbador no diferenciándose demasiado su actitud en este aspecto de de la elite gobernante. ${ }^{40}$

Los interrogantes siguen abiertos ¿cómo afecta el problema étnico el proceso de formación de clases? ¿Qué papel jugaron las cuestiones referidas a la etnicidad en el proceso de integración del trabajador inmigrante en la nueva sociedad? ¿Cuál es el rol que jugaban las diferencias étnicas en el lugar de trabajo no sólo en los momentos en los que emerge el conflicto sino en la experiencia laboral cotidiana? Y más estrictamente esas diferencias étnicas que dividían a la sociedad en general se reflejaban en las fábricas ¿cuáles fueron sus manifestaciones y cuáles las consecuencias?.

La cuestión de la etnicidad es un tema complejo, y en los marcos de un examen microhistórico sólo constituyen respuestas parciales a los problemas que plantea. En el

\footnotetext{
38 Juan Suriano. Anarquistas. Política y cultura libertaria en Buenos Aires, 1890-1910. Buenos Aires: Manantial, 2001.

${ }^{39}$ Rómulo Gandolfo. "Las sociedades italianas de socorros mutuos de Buenoa Aires: cuestiones declase y etnía dentro de una comunidad de inmigrantes (1880-1920)" en F. Devoto y E. Miguez, Asociacionismo, trabajo e identidad étnica. Buenos Aires: CEMLA-CSER-IEHS, 1992.

${ }^{40}$ Bilsky. El movimiento obrero judío en la Argentina. Buenos Aires: AMIA, 1987.
} 
estudio de los trabajadores de la industria frigorífica, ${ }^{41}$ se han establecido varias diferencias con los trabajos anteriores. El análisis de los conflictos obreros de 1917 muestra como los problemas del trabajo y la solidaridad de clase se alzaban por sobre las diferencias de origen. Pero la resolución no es tan fácil y mecánica, en la fábrica se creaban y recreaban nuevas identidades que significaban una definición sobre quienes formaban un nosotros que a veces se identificaba con la clase y otras se orientaba al grupo étnico nacional.

Sobre la historia de las mujeres

En los últimos años se ha discutido si la historia de las mujeres con la incorporación de la categoría de género ha producido una modificación del conocimiento histórico en general y de la historia obrera en particular. Si la historia de los trabajadores está sufriendo de cierta falta de vigor y de anemia, es cierto que la historia de las mujeres no puede sacarla del letargo pero puede contribuir a su recuperación. Comienzan a aparecer trabajos en congresos y revistas que denotan no sólo su existencia sino un marcado y creciente interés en el campo historiográfico local por desentrañar cual ha sido el rol histórico de "la otra mitad de la gente". Es cierto que la práctica de quiénes buscaban rescatar el protagonismo femenino fue colocar a las mujeres a la par de los varones como agente del cambio histórico y como objeto y sujeto de investigación, pero la historia de los trabajadores y pese a la apertura de campos temáticos y metodológicos que significó el desplazamiento hacia la historia social siguió impermeable al debate acerca de la mujer en la fuerza de trabajo o al rol de la misma en el desarrollo del capitalismo, o a las dificultades que significaba el uso de categorías universales como trabajador, clase, ciudadano.

Desde la historia se produjo una amplia literatura que aborda el trabajo industrial y el trabajo en la ciudad de Buenos Aires en general ${ }^{42}$ el trabajo doméstico ${ }^{43}$ las ideas

\footnotetext{
${ }^{41}$ Lobato. La vida en la fábricas. Trabajo, protesta y política en una comunidad obrera, Berisso (1904-1970). Buenos Aires: Prometeo Libros-Entrepasados, 2001.

42 Lobato. “Mujeres en la fábrica. El caso de las obreras del frigorífico Armour, 1915-1969”, Anuario, IEHS, № 5, Tandil, 1990, "Mujeres obreras, protesta y acción gremial en la argentina: los casos de la industria frigorífica y textil de Berisso" en Dora Barrancos. Historia y gênero. Buenos Aires: CEAL, 1993; María del Carmen Feijoo. "Las trabajadoras porteñas a comienzos del siglo" en Diego Armus. Op Cit, 1990.

${ }^{43}$ Marcela Nari. "Mujeres, trabajos y representaciones en la Argentina del siglo XX". Revista de Trabajo y seguridad Social, № 10, 1996.
} 
feministas, anarquistas y socialistas ${ }^{44}$ y comienzan a aparecer el rol de las mujeres en las huelgas y conflictos obreros. ${ }^{45}$ Esta tendencia se sumó a los trabajos sociológicos que se expandieron a partir de los años setenta. Sin embargo, la historia de las mujeres sigue ocupando un lugar marginal y debe responder a la pregunta en cierta forma descalificadota de ¿para qué sirve? La respuesta más elemental explicaría a la historia de las mujeres como el reconocimiento de que la sociedad está constituida por diferentes sujetos con acceso desigual al poder y los bienes culturales, simbólicos y materiales.

Con mayor o menor éxito los trabajos mencionados contribuyeron a colocar el tema de la mujer como un campo particular de estudio y a mostrar las complejidades de una sociedad donde la relación masculino/femenino está cruzada por zonas de conflictos y de complementariedades. Que las relaciones en el trabajo se constituyen como relaciones asimétricas de poder y que ellas están asociadas a las lecturas posibles de una sociedad democrática y plural. Por otra parte, la discusión sobre los roles productivos, las visiones del papel masculino/femenino o las relaciones de poder en los sindicatos constituyen el puente entre historia del trabajo e historia de mujeres que aún no se ha producido.

\section{Sobre la historia reciente}

La historia reciente de los trabajadores aún no ha sido estudiada sistemáticamente por los historiadores, aunque es materia de análisis de sociólogos y cientistas políticos. El pasado reciente, el que estuvo marcado por la violencia política, por la represión dictatorial y por la transición democrática es un territorio escasamente transitado, no sólo en el plano de la historia del trabajo sino también en su conjunto. Los argumentos de antaño se repiten: es necesario tomar distancia de los acontecimientos para tener cierto grado de objetividad. Sin embargo, podemos aceptar que cuando una etapa adquiere rasgos propios, claramente identificables de tal modo que se puede referir ella de manera general estamos en condiciones de abordar un estudio de ese período.

\footnotetext{
44 Dora Barrancos. Anarquismo, educación y costumbres en la Argentina de principio de siglo. Buenos Aires: Contrapunto, 1990. Feijoo, 1990.

${ }^{45}$ Silvana Palermo, ¿Trabajo masculino, protesta femenina? La participación de las mujeres en la gran huelga ferroviaria de 1917, Mimeo, Buenos Aires, 2004.
} 
No es sólo la reticencia a considerar a los fenómenos recientes como parte del pasado, buena parte de esos historiadores tienen que afrontar la difícil situación de evaluar su propia intervención en un pasado que está sujeto a un fuerte debate, sobre todo porque se asocia a él la posibilidad de construir una sociedad democrática y plural que elimine la posibilidad de retorno de los fantasmas dictatoriales del pasado.

En el plano específico de la historia obrera, aunque esta tendencia parece comenzar a revertirse, existen escasas investigaciones y la mayoría de ellas abarcan el período previo a la irrupción de la dictadura militar en 1976. En este sentido, los libros de dos historiadores de la academia norteamericana, uno sobre la resistencia y el sindicalismo peronista $^{46}$ y otro sobre el gremialismo combativo cordobés ${ }^{47}$ constituyen las menciones obligadas tanto por la rigurosidad como por la renovación historiográfica, así como también debería incluirse en esta línea el trabajo de Mónica Gordillo sobre la estructura gremial cordobesa en la primera mitad de los años $70 .^{48}$ Estos trabajos recorren diversos temas: la resistencia peronista, las relaciones entre las bases y la dirigencia gremial, las peculiaridades del movimiento obrero cordobés y una combinación en el análisis de la experiencia de los trabajadores, la actividad de los militantes y los dirigentes gremiales así como la utilización de recursos documentales y metodológicos más amplios que han hecho de estos textos referencias obligadas de la historia obrera argentina posterior al derrocamiento de Perón. Recientemente se ha publicado un trabajo que pretende ubicarse en la perspectiva de "la historia desde abajo" e intenta demostrar la interrelación entre la izquierda y la clase entre 1969 y 1976 y la "simpatía" que ésta habría demostrado hacia aquella. ${ }^{49}$ Uno de los grandes problemas de este texto es de tipo metodológico y se refiere al uso de las entrevistas que los autores realizaron con ocho militantes de izquierda de la época, en tanto pretenden demostrar el carácter solidario y no individualista de la clase obrera reproduciendo la versión de los propios actores. ¿Es posible darle voz a los actores de manera acrítica? ¿Cuál es el rol del historiador en este caso? ¿Es sólo un mero reproductor de la voz de los oprimidos? En todo caso este es un

\footnotetext{
46 James, op cit.

47 James Brennan. El Cordobazo. Las guerras obreras en Córdoba. Buenos Aires: Sudamericana, 1994.

${ }^{48}$ Mónica Gordillo. Córdoba en los '60: la experiencia del sindicalismo combativo. Córdoba: Universidad Nacional de Córdoba, 1996.

49 Pozzi-Schneider. Los setentistas. Izquierda y clase obrera: 1969-1976. Buenos Aires: Eudeba, 2000.
} 
terreno en el que debiera producirse un debate entre aquellos interesados en la historia obrera.

No es el único problema, hace una década Cecilia Cangiano ya había señalado las virtudes y las limitaciones de esa producción ${ }^{50}$ en referencia a otro texto. ${ }^{51}$ Pero el rasgo fundamental de esta forma de encarar la historia obrera es cierto esencialismo, en cuanto supone que la clase no solamente está siempre presente (como el sol a la mañana) sino que resiste permanentemente los embates de represores y patrones, perdiendo de vista las complejidades de un proceso histórico caracterizado por trasformaciones tanto de tipo estructural como coyuntural y que, indefectiblemente, trasforman a la clase obrera modificando sus conducta (tanto individual como colectiva) y alterando la cohesión. Esta última, así como la conciencia de clase no existen porque si, ni permanecen inalteradas e inmunes a las presiones que un proceso represivo como el iniciado en 1976 desató sobre la sociedad toda y sobre los trabajadores en particular. Esta forma de entender la historia obrera malinterpreta o desconoce las tradiciones políticas, ideológicas y culturales de la clase obrera que nos demuestra que la formación y la conciencia de clase no es un proceso acumulativo y progresivo sino que reconoce situaciones cambiantes.

Se torna necesario impulsar y encarar la investigación y el análisis del mundo del trabajo en el último cuarto de siglo así como también debatir las diversas perspectivas teóricas y metodológicas desde las cuales se pueda abordar este proceso. Si se realizara una periodización de la historia obrera contemporánea tal vez tendríamos que pensar en el largo período que va desde la caída de Perón hasta el fin de siglo caracterizado por el predominio de las organizaciones gremiales peronistas y sus vínculos permanentes con el poder político, por los debates asociados a los cambios operados en los lugares de trabajo (organización y control de la producción) y por las relaciones entre trabajadores y dirigentes gremiales. No obstante pueden delimitarse períodos más acotados 1955-1969, 1969-1976, 1976-1983, 1983-89 y 1989 en adelante; en cada uno de esos períodos un acontecimiento o una serie de acontecimientos aparecen como focos principales: la resistencia peronista y la conformación del movimiento sindical peronista, el cordobazo y

\footnotetext{
${ }^{50}$ Cecilia Cangiano. "Pensando a los trabajadores: la historiografía obrera contemporánea. Argentina entre el dogmatismo y la innovación”, Boletín, № 8, Instituto de Historia argentina y Americana Dr Emilio Ravignani, 2 do semestre de 1993.

51 Pablo Pozzi. Oposición obrera a la dictadura. Buenos Aires: Contrapunto, 1988.
} 
el desarrollo del clasismo, las formas invisibles de la protesta obrera durante la represión de la dictadura militar inaugurada en 1976, las huelgas generales de la CGT en contra del gobierno de Raúl Alfonsín, los nuevos movimientos sociales generados a partir de la desestructuración del mundo del trabajo clásico y de la aplicación de las políticas neoliberales durante los años 90.

La recomposición de la clase obrera, sus expresiones culturales, sus acciones pueden constituirse en temas fundamentales para analizar todo el período pero es necesario además incorporar una dimensión espacial más amplia. Las prácticas de los trabajadores, su particular experiencia laboral y política no puede ser subsumida en los focos de protesta como los de la ciudad de Buenos Aires, Córdoba o Rosario. Desde los años sesenta los cambios en las economías regionales han producido transformaciones de importancia en las condiciones de trabajo de la actividad monoproductora vinculada al azúcar en Tucumán, al algodón en Chaco o al tabaco en Misiones, adquirieron peso el trabajo en las empresas estatales asociadas a la explotación de petróleo, carbón y a la producción de acero y un examen del proceso histórico en un espacio más amplio puede ayudar a dibujar la magnitud de los cambios que generaron la aplicación de políticas neoliberales y el avance arrollador de los procesos de privatización que acompañó la presidencia de Menem. ${ }^{52}$

\section{UNIR LOS FRAGMENTOS Y RECUPERAR EL SUJETO}

¿Cuál hoy es el rumbo de la historia de los trabajadores? Pese a las dificultades planteadas es posible que sea la hora de realizar una síntesis de lo hecho puesto que aun no se ha escrito una historia de los trabajadores que integre todos los fragmentos dispersos. Esa nueva interpretación de la historia de los trabajadores tiene que incorporar necesariamente las investigaciones que no tuvieron como objeto ni como sujeto a los trabajadores; se nutrirá de la historia social, de la historia política, de la historia regional y

\footnotetext{
52 En diversas universidades regionales se produjo una importante cantidad de trabajos monográficos y artículos desde el punto de vista local y regional sobre los trabajadores vinculados a las industrias de petróleo, del carbón, de la pesca, de la fruticultura, del azúcar, del algodón, del tabaco o de la actividad vitivinícola (No haré aquí una mención de todos esos trabajos porque excede el objetivo de esta comunicación). Ahora bien, resta aun la ardua tarea de integrar esos trabajos con el fin de tener una mirada del conjunto del mundo laboral.
} 
de la historia de las mujeres. Tendrá que ser más flexible y abierta a los problemas planteados en otros espacios de investigación. Esa flexibilidad y apertura intelectual tiene que ejercerse también dentro de la propia historia de los trabajadores pues a veces nuestro propio trabajo se plantea en franca oposición. Debido a cierto enclaustramiento de la historia de los trabajadores en la Argentina sería pertinente encarar un diálogo más fuerte entre quienes miran cuestiones más estructurales (procesos de trabajo, relaciones laborales, organizaciones) y quienes parecen orientarse a las dimensiones culturales. El estudio de diferentes grupos de trabajadores, de diferentes ramas industriales, del pensamiento empresario, los sistemas de valores, las ideas de empresarios y trabajadores (varones y mujeres), la conformación de instituciones y profesionales vinculadas al mundo del trabajo, las relaciones entre Estado y trabajadores y los vínculos entre trabajadores y política son los temas y los problemas que necesita desarrollar la historia de los trabajadores para recuperar su propia dinámica. De modo que es necesario repensar la historia de los trabajadores buscando integrar los aportes de la nueva historiografía en una visión globalizadora de los procesos históricos. Simultáneamente, la historia político institucional debe estar atenta al examen de la constitución de un ámbito público de los trabajadores, de sus mecanismos de acción, de las formas con que buscan moldear a sus bases los dirigentes gremiales, de su vinculación con las fuerzas políticas.

Si partimos de la reflexión sobre las condiciones de producción en Argentina y sus resultados concretos, la posibilidad de producir una lectura renovadora de la historia laboral que se había anquilosado alrededor del examen de las organizaciones sindicales, que tenía un sesgo temporal y temático articulado en torno del fenómeno del peronismo, requiere tanto una revisión crítica de los supuestos teóricos de los estudios más tradicionales sobre la clase obrera como una escasa reverencia a los nuevos paradigmas que el giro lingüístico propone, por otra parte sin ningún peso en las historias producidas en nuestro país, pero abierta a la importancia del lenguaje para examinar los deslizamientos que recorren la experiencia obrera cuando se habla de identidades. ${ }^{53}$

Para ejemplicar lo que quiero decir en este aspecto me parece que, como ha demostrado Mirta Lobato, un análisis de las fábricas puede ayudar a producir una

\footnotetext{
${ }^{53}$ Gareth Stedmen Jones. Lenguajes de clase. Estudios sobre la historia de la clase obrera inglesa. Madrid: Siglo Veintuno, 1989.
} 
combinación de las propuestas historiográficas en debate pero no como una fusión sino como un constante tránsito entre lo micro y lo macro histórico, entre primeros planos de objetos y sujetos y miradas más distantes y extensas. ${ }^{54}$ Si se coloca a la fábrica como protagonista se puede tejer el entramado de relaciones que en ella tienen lugar. A partir de la fábrica se puede recuperar al sujeto trabajadores pero ellos no están construidos como sujetos ni como objeto de estudio separados de los empresarios. Como sostiene E. P.Thompson, no podemos tener amor sin amantes y como la relación histórica que está implícita en su noción de clase debe estar siempre en gente real y en un contexto real es importante entender las relaciones de producción -incluidos los vínculos entre empresarios y trabajadores- y las tradiciones, sistemas de valores, ideas y formas institucionales que resultan de su experiencia de trabajo. Pero el trabajo organiza la vida y las narraciones locales -barrio, localidad- y lo que los trabajos sobre cultura barrial separaban se unen de manera tal que los análisis se deslizan de la fábrica a la comunidad y viceversa. ${ }^{55}$

Un concepto clave para leer una unidad de producción, la fábrica por ejemplo, es el de proceso de trabajo. Esa noción se encuentra en el centro de los debates actuales sobre las transformaciones del proceso industrial. Lo que era un antiguo enclave de interés sociológico se convirtió en un elemento fundamental en los debates sobre el pasaje del viejo a un nuevo paradigma industrial. El análisis sobre la construcción histórica de los principios, técnicas y formas organizativas de la relación capital-trabajo puede matizar tanto la historia de los trabajadores como la historia de la industria y, al incorporar también las producciones discursivas es posible entender de qué modo y a través de que circuitos se acuñaron y difundieron conceptos tales como eficiencia, racionalidad, modernización y progreso así como se establecieron que ellos eran centrales para la acumulación de capital.

El análisis de las fábricas ayuda a delinear el cuadro de las representaciones habituales de los sistemas productivos en términos de una dominación ejercida sobre un conjunto de trabajadores. Las propuestas teóricas de erradicar el sesgo androcéntrico existente en el debate sobre procesos de trabajo tienen también una materialización que las historias sobre trabajadores rara vez juntan como parte de un análisis integral. Como

\footnotetext{
${ }^{54}$ Lobato. La vida en la fábricas. Trabajo, protesta y política en una comunidad obrera, Berisso (1904-1970). Buenos Aires: Prometeo Libros-Entrepasados, 2001.

${ }^{55}$ E.P. Thompson. La formación de la clase obrera en Inglaterra. Barcelona: Crítica, 1980.
} 
propuesta política el planteo de metas de equidad social que contemplen la igualdad de género, o mejor aun, la necesaria equidad entre hombres y mujeres porque ella se inserta en la más conocida división sexual del trabajo, requieren de la ruptura de la matriz analítica naturalizada e implícita existente en las teorías, prescripciones, definiciones e interrogantes planteados en la literatura existente. 